\title{
Resenha
}

\section{Política pública como campo na formação, atuação e produção de conhecimento em Psicologia'}

\author{
Public policy as a field in training, practice and \\ knowledge production in Psychology
}

Mônica Soares da Fonseca BEATO

Como entender a singular aproximação que vem sendo construída entre a Psicologia e as políticas públicas sociais em nosso País? Quando a Constituição Brasileira completa 25 anos, ainda é expressivo o contingente de profissionais que insistem em buscar uma resposta pronta e objetiva acerca de seu "papel" em determinado programa social. E não é diferente o tom dos questionamentos em muitos espaços de formação, algumas vezes reforçados por uma docência que se concebe como função meramente instrumental.

O livro "Psicologia, políticas públicas e o SUS", de João Leite Ferreira Neto, traz contribuições importantes para refletir em que medida a institucionalização das políticas sociais de Saúde tem reverberado na revisão dos processos de atuação, formação e produção de conhecimento em Psicologia. Tendo Michel Foucault como interlocutor privilegiado, o autor se situa na contramão das corporações disciplinares e da estagnação do pensamento em conceitos. Assume também, com o filósofo francês, o princípio analítico de abandonar binarismos na forma de entender a realidade. $\mathrm{O}$ esforço de Ferreira Neto para não perder de vista o conjunto da obra de Foucault leva o leitor à construção desse pensamento sobre uma gama variada de tecnologias de si, as quais remetem às "práticas psicológicas".

No Brasil, a Psicologia começou a mudar seu perfil na década de 1980, como resposta às mudanças de uma sociedade marcada pelo fim do milagre econômico e pela ascensão dos movimentos sociais. A formação calcada na concepção clássica de Psicologia Clínica vai dando lugar a novas possibilidades. As práticas emergentes formam, desde então, um "painel multifacetado e em construção" (p.160). Nesse contexto, conclui o autor, a presença do psicólogo nas políticas públicas não é progressista por natureza, tanto devido às inflexões que as demandas sofrem ao se institucionalizarem no aparelho estatal, enfraquecendo parte de sua potência inovadora, quanto pela possibilidade de existir a simples adaptação flexível para alcance de novos mercados.

$\boldsymbol{\nabla} \boldsymbol{\nabla} \boldsymbol{v}$

1 Ferreira Neto, J. L. (2011). Psicologia, políticas públicas e o SUS. São Paulo: Escuta.

2 Faculdade de Estudos Administrativos de Minas Gerais, Curso de Graduação em Psicologia. R. Santa Rita Durão, 1160, Savassi, 30140-111, Belo Horizonte, MG, Brasil. E-mail:<msoaresbeato@gmail.com>. 
Para trazer elementos concretos à discussão, as ações em Saúde do Sistema Único em Saúde (SUS) em Belo Horizonte (MG), são focalizadas em três capítulos. Um deles apresenta o movimento de produção de novas referências clínicas e extraclínicas dentro dos próprios serviços. É interessante compreender como a implantação cotidiana de um programa pode diversificar o arsenal teórico-técnico e ético das profissões. O histórico feito pelo autor sobre a trajetória desse município mostra descontinuidades, avanços e impasses em questões como a atenção aos casos leves e graves, o atendimento em grupos e a concepção de clínica que subsidia o projeto antimanicomial local. Mais do que a descrição em si do percurso da rede municipal, são as considerações do autor que estimulam o leitor a desnaturalizar aquele processo. É o caso da ponderação de que o ingresso dos psicólogos na área de Saúde Mental cerceou um trabalho mais inventivo desses profissionais na rede de saúde em geral.

Em outro momento, são investigadas mais especificamente as práticas clínicas desenvolvidas por psicólogas da atenção primária em Belo Horizonte (MG). Embora possam ser recapturadas por um modelo clássico de clínica, essas práticas incluem outros elementos que as tornam heterogêneas. Elas tendem a ser menos subsidiadas por instrumentos técnicos a priori, produzindo conexões com as políticas públicas, com outros atores e com os processos socioeconômicos que perpassam a vida na cidade. Tais interferências não se impõem como dificuldades à clínica quando são incorporadas como seu componente. Nesse caso, a clínica será transversalizada - avalia o autor, tomando de empréstimo um termo de Felix Guattari -, a depender do grau de articulação entre as múltiplas dimensões que a compõem.

Se acima se encontra o termo intervenções clínicas, o capítulo seguinte irá focalizar as intervenções psicossociais. Uma experiência na atenção primária em Belo Horizonte (MG), é refletida por quem dela participou na condição de psicólogo de um centro de saúde. A ação foi norteada pela tentativa de superar o antagonismo aparente entre o que a Saúde oferecia e o que uma escola estadual da região demandava. A escola se queixava de recor606 rentes problemas de aprendizagem e manejo da disciplina, além de dificuldades no trato com a sexualidade. São aqui problematizados os resultados e os impasses de um dispositivo pautado pela postura de corresponsabilização, autoanálise e autogestão, com tempo delimitado, em que o grupo interventor se colocou na condição de agente catalisador do coletivo local.

Ferreira Neto também discute a atual tendência, em parte da produção de conhecimento na Psicologia brasileira, à superação da noção de subjetividade como interioridade psicológica, a partir da influência das ciências humanas e sociais. Um ensaio sobre a conjunção território-subjetivação, no segundo capítulo, acena para a relação imanente entre subjetividade e espaço social. Notam-se aqui algumas balizas fundamentais para o refinamento do conceito de territorialização em programas sociais, de modo que as ações possam incorporar os aspectos socioculturais locais.

A formação em saúde, imprescindível para a realização do projeto do SUS, tem sido alvo de políticas específicas que tendem a provocar mudanças em muitos cursos de Psicologia. Um dos capítulos, o único escrito em coautoria com Luciana Kind, situa o leitor em relação às políticas de formação de recursos humanos em saúde no país. Destaca-se a menção ao pressuposto, fortalecido na década de 1980, de que a formação deveria ir além da mudança no enfoque teórico, produzindo sujeitos políticos. Aliás, vale complementar que essa ideia é mais carregada de sentido em um efervescente contexto de difusão do Movimento Sanitário do que nos dias atuais. Um diagnóstico dos autores sobre a atual estratégia de incentivo à formação - o Programa Nacional de Reorientação Profissional para a Saúde (Pró-Saúde) -, coloca o leitor diante da complexa tarefa colocada por esse programa. Longe de se contentar em elencar as distâncias entre os virtuosos objetivos do programa e a realidade, a proposta avaliativa é outra. Os autores entendem que os objetivos do Pró-Saúde são desafios a serem enfrentados de modo permanente, isto é, são imagens-objetivos. É especialmente valioso o comentário sobre a existência de tensões ligadas a crônicas relações de poder entre instituições formadoras e serviços. Ainda que seja difícil vivenciar tais 
circunstâncias, os entraves precisam mesmo emergir para que se revejam as fragilidades e as potências das estratégias de formação.

Outro capítulo é ainda mais propositivo. Segundo o autor, estar-se-ia presenciando certo investimento na redefinição do modo de produzir interfaces entre teoria e prática, com apostas de formação sustentadas por uma relação dialógica entre ambas. Seria possível, ainda, superar discursos calcados na segmentação entre os diferentes campos, como é o caso das posições excludentes entre Psicologia clínica e social. Esses são os dois grandes obstáculos a serem transpostos pelas instituições formadoras. Ainda que a organização do currículo por competências e habilidades, preconizada pelas atuais Diretrizes Curriculares (Brasil, 2004), tenha surgido como política de subjetivação neoliberal, Ferreira Neto aposta na reapropriação crítica desses termos. Aqui se pensaria em competências e habilidades mais plurais e interdisciplinares, que não escapem às perguntas: "que profissional desejamos formar? E para qual sociedade?" (p.42).

A aproximação mais concreta da obra se dá pela área da saúde, campo privilegiado de pesquisa e intervenção do autor. Entretanto, é no rigor com a teorização que se observa um estilo de escrita que transcende os questionamentos internos ao setor, provocando inquietação sobre a interface entre Psicologia e políticas públicas de modo mais amplo.

Talvez a maior riqueza da obra se encontre na difícil superação do olhar unilateral sobre as relações entre formação, atuação e pesquisa. Concebendo seu objeto como um campo de forças móvel e transitório, o autor procura tornar permeáveis as fronteiras entre esses vários espaços. Além de apresentar textos instigantes para os atores da formação e da prática profissional, trata-se de uma inspiração para aqueles que desejam pesquisar, desprendendose da reafirmação do mesmo.

\section{Referências}

Brasil. Conselho Nacional de Educação. (2004). Resolução $n^{\circ} 8$, de 7 de maio de 2004. Institui as diretrizes curriculares nacionais para os cursos de graduação em Psicologia. Brasília: Ministério da Educação. Recuperado em fevereiro 3, 2012, de http://portal.mec.gov.br/cne/ arquivos/pdf/rces08_04.pdf

Recebido em: 8/2/2013

Aprovado em: 19/3/2013 
